\title{
GALLERY EDUCATION: HOW GALLERY EDUCATORS APPROACH SPECIAL EDUCATION TEACHERS IN GALLERY SETTINGS?
}

\author{
Bahrom Mohd Isa \\ Liverpool John Moores University, United Kingdom
}

\begin{abstract}
This paper is part of an ongoing doctoral study that looks into the approaches employed by gallery educators at Balai Seni Visual Negara (BSVN) in conducting their educational programmes to a number of special education teachers from a school that specialises in special education. As such, the three primary aspects that function as the focus of the study are: i) perceptions of gallery educators upon the expectations of the school principal, the teachers, and the parents; ii) the organization of the programme in BSVN; as well as iii) its impact upon both special education teachers and administrators. Meanwhile, the methods utilised for data collection are interviews, diary entries, observation, and document analysis. In addition, this study adopts the qualitative case study design with the naturalist paradigm. With that, the discussion generated in this paper only emphasises on the early pre-test data derived from one-to-one interview between a gallery educator and a special education teacher.
\end{abstract}

Keywords: gallery education; special education teacher; art education; qualitative research;

\section{INTRODUCTION}

Gallery education is a significant value that carries essential weight in schools that specialises in special education. This is because; it can be used to inspire special education teachers who are involved directly in teaching art subject in their special education school throughout Malaysia similar to other core subjects (such as mathematics, language, history). For instance, this subject initiates the movement of the eye, which can be trained via multiple visual art activities; generates ear test through listening to music, develops coordination of body movement, as well as practice of facial expression through theatre and drama arts [1], [7].

Furthermore, the number of gallery education abroad has risen substantially within a year. For example, several art galleries at the United Kingdom have focused on educational activities, besides developing some good models and practices [2], [12].

Moreover, the educational activities carried out in these galleries found in the United Kingdom have displayed highly positive impact to various backgrounds of the audience. This includes informal visits from the public, group visits, as well as various educational practises from both private and government agencies. In fact, this new activity has been seen to be expanding at a rapid rate with a spark of interest from the society especially upon contemporary art painting exhibited in several galleries in the United Kingdom, including several European countries. On top of that, such activity is also supported by art communities through the establishment of Contemporary Gallery Education (GCE) [3], [8]. 


\section{GALLERY EDUCATION AS AN ALTERNATIVE}

Additionally, several other elective subjects like art therapy and theatre for special education students have been implemented in Malaysian special education schools. Furthermore, the present study demonstrates that art has functioned as a therapy for solving certain prevalent issues in special education, surprisingly, with early implementation before changes that have been adopted within the present modern approach. Hence, gallery education, as part of the study, theoretically could help to bridge and revise the future development of special education programme for special education teachers, besides preparing one with new knowledge of contemporary art scene, as well as prominent figures of visual art artists both local and international levels [4], [9].

\section{METHOD}

As for this study, a case study was employed by the researcher, whereby the participants are comprised of a Balai Seni Visual Negara (BSVN) gallery educator and a Malaysian special education teacher. As such, the qualitative research design was implemented in carrying out this study and the participants were interviewed. The criterion set for those involved in this study is that they should have at least one to seven years' of working experience in their respective fields. Besides, the two participants gave consent to be involved in this study by completing the consent form. Most importantly, the identities of the participants are kept confidential to protect their privacy [5], [10].

As for the interview session, both the participants were interviewed at their workplaces individually. After obtaining their permission, all conversations were recorded using voice and video recorders. The researcher also noted some important details during the interview protocol. After that, the recorded interview was transcribed and noted. The interview was held from September 2016 onwards after obtaining permission from the following agencies: BSVN, Economic Planning Unit (EPU), Economic Planning and Research Division (EPRD), as well as Special Education Division (BPK) from the Malaysian Ministry Of Education [9], [11].

\section{DATA ANALYSIS AND DISCUSSION}

As for data analysis, the atlas.ti software programme was employed in a semimanual manner. The recorded interview was transferred into the researcher's personal computer. Later, the document was transcribed with atlas.ti software. The coding process took several days, and after that, several different categories and themes emerged. Later, the codes and the themes were identified, separated, and categorized [6].

The primary goal of this research is to look into the educational plan or programme implemented by gallery educators in BSVN within a year, if any. This pretest data collection is still an ongoing process, as depicted in the timeline set earlier with the supervisor and gatekeeper until the objective of this study is successfully achieved.

As a result, the findings exemplify two main themes, namely planning and implementation, followed by sub-themes, which are collaboration, exhibition, knowledgeable, art education, education programme, finance, and attitudes. The related findings are further elaborated in the following: 
a) In the collaboration category, 11 codes had been associated with special education, for instance, a visit from non-government organization (NGO) in relation to autistic children and a partner programme with the Ministry of Tourism in establishing One Malaysia Contemporary Art Tourism (1MCAT), which were successfully carried out. Moreover, a special education teachers also joined the programmes organised by NGOs, such as National Dyslexia Society of Malaysia (NASOM), in order to gain fresh insights pertaining to the pedagogy of special education.

b) In the exhibition category, several activities were conducted, such as those listed in the following: discussion with art collector, discussion about new exhibitions that has a huge impact upon BSVN audience, selection of permanent BSVN collection from artist artworks, as well as tour with artists at every state via 1MCAT. In fact, these programmes had been successfully carried out. Nonetheless, the special education teachers were clueless about art exhibition, except for some who have already visited some art exhibitions in private galleries.

c) In the knowledgeable category, the gallery educators have obtained their basic education in portraiture, batik canting, as well as educators in BSVN. Besides, the special education teachers also possess fundamental art knowledge with experience in teaching the art subject at school.

d) In the art education category, the gallery educators gave explanation to visitors about the meaning of art, introduced visitors to several artists and their works, besides explaining the present progress in arts within the Malaysian setback. As such, special education teachers can deepen their knowledge about art by joining art workshops conducted in schools, studying syllabus prepared by BPK, and by gathering art information via websites.

e) In the education programme category, numerous activities, such as after-visit workshop, focused workshop for children undertaking special education, seminars, and guided visit by gallery educators, were successfully carried out. Moreover, workshops organised by JPN, PPD, and certain schools were also participated by special education teachers.

f) In the finance category, BSVN is fully funded by the Malaysian government, under the Malaysian Ministry of Tourism and Culture. Besides, no entrance fee is charged for both public and school visitors. These special education teachers are also government servants, whose wages are paid by the Malaysian Ministry of Education, together with special monthly allowance. Nonetheless, before organising any activity, they would have to seek approval from school administrator, PPD, JPN, and BPK.

g) In the attitudes category, some public visitors seemed to lose interest while briefing is given by gallery educators during the gallery visit, for they were keener on their personal agenda. Meanwhile, as for special education teachers, they have to adhere to standard operating procedure during outdoor activities because they need to ensure extra safety in handing students with disabilities. 


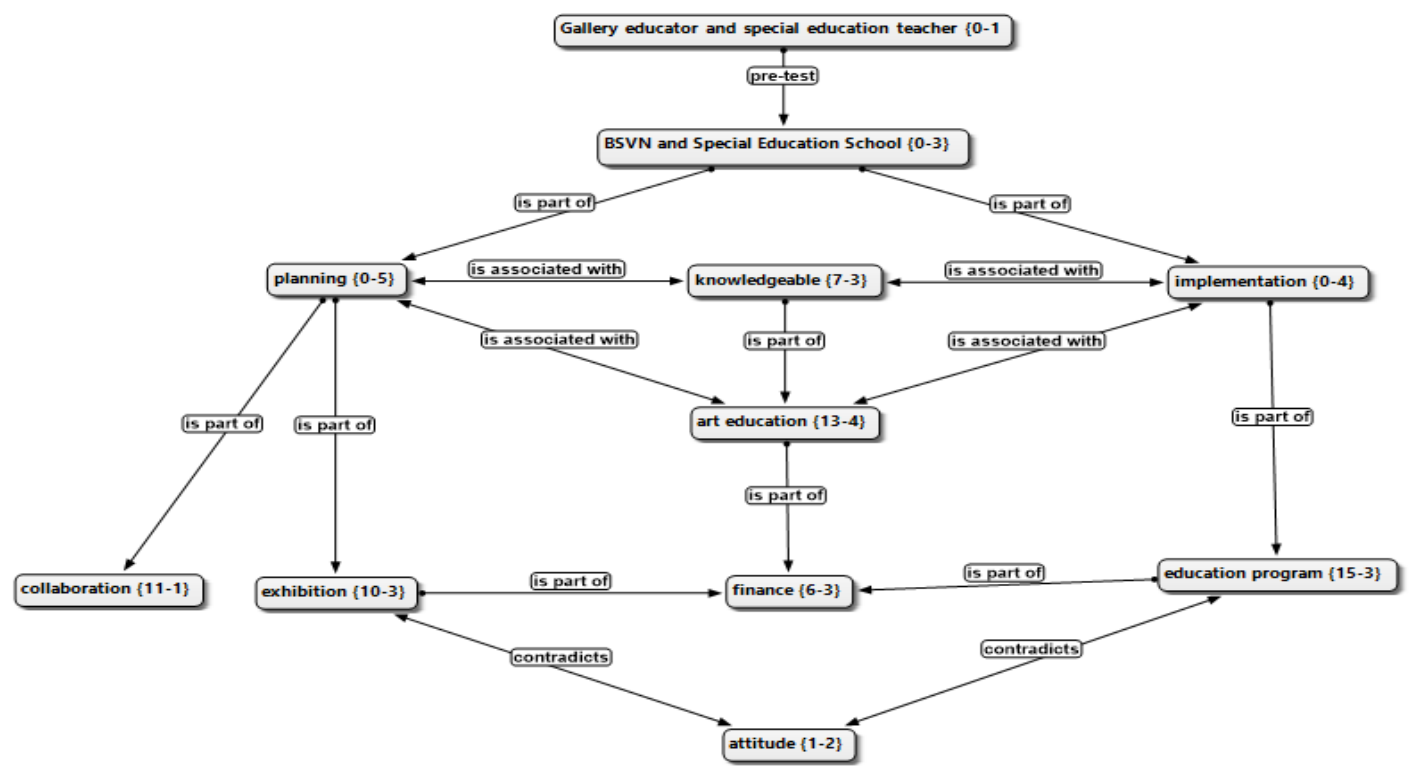

Figure 1: Themes and codes retrieved from pre-test interview transcription using QDA software.

On top of that, the preliminary findings demonstrate that all the programmes that were planned by gallery educators had been based on multiple target audience like visitors from schools, universities, and those with disabilities. Additionally, the researcher believes that gallery education offers extra benefits for special education teachers especially in inspiring them, besides adding more value in art education for themselves during their teaching process in classrooms, as well as to function as a catalyst for their special children in exploring their creative talents and skills. Other than that, in order to boost more value, these special education teachers, either from school or administrator level, should collaborate with BSVN for the sole purpose of encouraging their students to be more creative, to be more confident, as well as to be able to create some artworks that can contribute to their society, school, or even at the international level. Besides, a recent study conducted by an independent researcher revealed that education within the gallery setting can help one suffering from dyslexic in becoming more focused, besides reducing their stress level. As such, gallery education has the potential to emerge as a new resource for special education teachers to educate a person or a student with disabilities to express their creative talents within the school setting [4].

\section{TRUSTWORTHINESS AND TRANSFERABILITY}

Nevertheless, although this is indeed an ongoing research, the content of this study should not be compromised as it is still consistent, whereby both participants provided almost similar codes. Furthermore, this study has limited its sample to merely two participants by weighing in the suggestion offered by the Director of Studies. Hence, more interviews would have to be conducted to attain results that are more reliable. Thus, the findings retrieved would evolve from time to time after the researcher adds more information from the main study. Besides, in order to validate the data, both the transcription scripts were double-checked by two different supervisors and they also noted similar codes and themes. Therefore, this study is not biased and besides, the findings are definitely reliable and genuinely retrieved from original and primary resource [5]. 


\title{
6. CONCLUSION AND FUTURE RECOMMENDATIONS
}

The findings retrieved from this study suggest that special education teachers are not keen in visiting galleries because they do not receive any information or are aware of the significance of visiting galleries. Moreover, no special occasion has ever been highlighted associated to galleries, and for that matter no programme similar to that emphasised in this research has been carried out in public schools. Nonetheless, these limitations should not be compromised, but they should be given the opportunity at least once a year to visit gallery, especially the BSVN.

In addition, some educational programmes for special education teachers should be organised with gallery educators in providing early exposure to gallery education on an annual basis.

Therefore, gallery educators and special education teachers should start a smart partnership or join venture together in order to strengthen, as well as to benefit special education teachers and the students in future.

\section{ACKNOWLEDGEMENTS}

I would like to thank my Director of Studies, Dr. Mark Meadows (Liverpool John Moores) and external supervisor, Dr. Jane Mc Donnell (Manchester Metropolitan University) for giving many effort for this paper and finally, we made it happen! Sincere from my deepest heart, to my lovely wife, Azliah Maya which is waiting to deliver our $3^{\text {rd }}$ baby soon, and to all my handsome kids Farrel Aqlan and Fierasz Naufal who are my strongest supporter from emotional and physical side of me, since I was starting my $\mathrm{PhD}$ studies from September 2015 until today. Hope this new research would contribute a new knowledge to art society and special education in future, mainly in Malaysia.

\author{
ABBREVIATIONS \\ BSVN Balai Seni Visual Negara \\ EPU Economic Planning Unit
}


EPRD Economic Planning \& Research Department

NGO Non-governmental organization

BPK Bahagian Pendidikan Khas

CGE Contemporary Gallery Education

KPM Kementerian Pendidikan Malaysia

1MCAT One Malaysia Contemporary Art Tourism

JPN Jabatan Pendidikan Negeri

PPD Pejabat Pendidikan Daerah

NASOM National Dyslexia Society of Malaysia

\section{REFERENCES}


[1] Okvuran, A. (2010). The relationship between arts education, museum education and drama education in elementary education. Procedia - Social and Behavioral Sciences, 2, 5389-5392.

[2] Pringle, E. (2006). Learning in the Gallery: Context, Process, Outcomes: London, UK: Engage.

[3] Dickson, M. (ed.) (1995). Art with People. Sunderland: AN Publications.

[4] Berita Harian (2016, October 16). Sisipan akhbar GPS Bestari.

[5] Creswell, J. W., \& Miller, D. L. (2000). Determining validity in qualitative inquiry. Theory into Practice, 39(3), 124-130.

[6] Retrieved on 22/10/2016 from http://www.zackzairul.com/about.html.

[7] Allen, F. (2008). Situating gallery education. Tate Encounters, 1970(2), 1-12.

[8] Badrul, I. \& Forrest, D. (2011). A qualitative case study of the implementation of education programs at the National Gallery of Victoria (NGV), Australia. Procedia - Social and Behavioral Sciences, 29, 1905-1913.

[9] Data Pendidikan Khas (2014). Putrajaya: Bahagian Pendidikan Khas, Kementerian Pendidikan Malaysia.

[10] Norwich, B., \& Nash, T. (2011). Preparing teachers to teach children with special educational needs and disabilities: The significance of a national PGCE development and evaluation project for inclusive teacher education. Journal of Research in Special Educational Needs, 11(1), 2-11.

[11] Myllyntaus, O. (2012). Visual Arts Education Reasoning the Acquisition and Placement of Public Sculptures - Case of the Public Sculptures of the Jyväskylä City Art Collection in 1977-2007. Procedia - Social and Behavioral Sciences, 45, 605-614.

[12] Möersch, C., \& Sharp, M. (2003). Gallery education. International Journal of Art and Design Education, 22(2), 208-214. 